\title{
Gastric volvulus: an easily missed diagnosis of chest pain in the emergency room
}

\author{
Raktim K Ghosh, ${ }^{1}$ Kulsoom Fatima, ${ }^{1}$ Keyvan Ravakhah, ${ }^{1}$ Chandra Hassan ${ }^{2}$
}

${ }^{1}$ Department of Internal Medicine, St Vincent Charity Medical Center, Cleveland, Ohio, USA

2Department of General Surgery, St Vincent Charity Medical Center, Cleveland, Ohio, USA

\section{Correspondence to} Dr Raktim K Ghosh, raktimghoshmd@gmail.com

Accepted 18 December 2015

CrossMark

To cite: Ghosh RK, Fatima K, Ravakhah K, et al. BMJ Case Rep Published online: [please include Day Month Year] doi:10.1136/ bcr-2015-213888

\section{DESCRIPTION}

Chest pain is one of the leading causes of emergency room (ER) visits in the USA, resulting in more than 6 million annual visits. ${ }^{1}$ Often, rare causes of chest pain that initially look deceptive get missed in ER.

Para-oesophageal hernia is characterised by upward dislocation of the gastric fundus with normal position of the gastro-oesophageal junction. ${ }^{2}$ Most patients with para-oesophageal hernia are either asymptomatic or symptomatic with acid reflux. One of the rare complications of this condition is gastric volvulus, which is due to an acute abnormal rotation of the stomach either on vertical or horizontal axis, causing complete gastric outlet obstruction and, potentially, strangulation. ${ }^{3}$

Acute gastric volvulus, being a rare condition, may be missed as a cause of chest pain, shortness of breath (SOB) and severe retching in the ER. Mortality and significant morbidity-including perforation, necrosis and sepsis-related to acute gastric volvulus, are high. ${ }^{4}$

A 32-year-old man with a longstanding history of gastroesophageal reflux disease (GERD), presented to our ER, with acute onset, progressively worsening left-sided chest pain and SOB for $24 \mathrm{~h}$. He was found to be severely hypotensive and tachypnoeic, with complete absence of breath sound over the left chest. This was his third ER visit. He was sent home from the earlier two visits with a diagnosis of acid reflux, as he was found to have a normal chest $\mathrm{X}$-ray, and normal ECG, troponin, D-dimer, metabolic panel and complete blood count. The chest pain and SOB started getting worse after he tried self-induced retching a couple of times.

The chest X-ray this time showed marked elevation of the left hemidiaphragm with herniation of the distended large part of the stomach into the thorax (figure 1). The lateral view chest and abdomen X-ray showed a single large hemispherical gas bubble in the chest and upper abdomen, characteristic of gastric herniation (figure 2). CT of the thorax and abdomen with contrast showed herniation of nearly the entire stomach with air and fluid into the left thoracic space (figure 3). A possible diagnosis of acute gastric volvulus was made. Initially, a blind nasogastric tube insertion was not attempted fearing perforation. The patient was immediately taken to the operating room. Cardiothoracic and gastrointestinal surgeons were consulted. First, an endoscopy was attempted to decompress the stomach as much as possible. The endoscope showed the gastro-oesophageal junction at $40 \mathrm{~cm}$. On advancing the endoscope and suctioning, $2.5 \mathrm{~L}$ of bloody coffee-ground gastric fluid was aspirated. A laparoscopic reduction of the

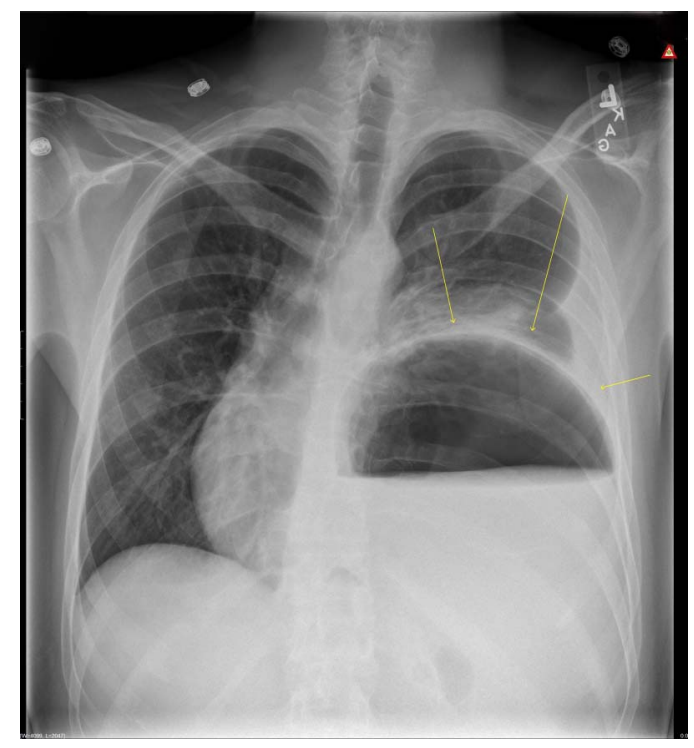

Figure 1 Chest X-ray posteroanterior view: a hugely distended and large part of the stomach seen in the thorax and atelectasis of the left lung base.

hernia was then attempted. The majority of the stomach content was found in the thorax instead of in the abdomen. The constricting ring was cut open and volvulus untwisted. Immediately, a gush of air was expelled from the distal to proximal part of the stomach. It was reduced back to the

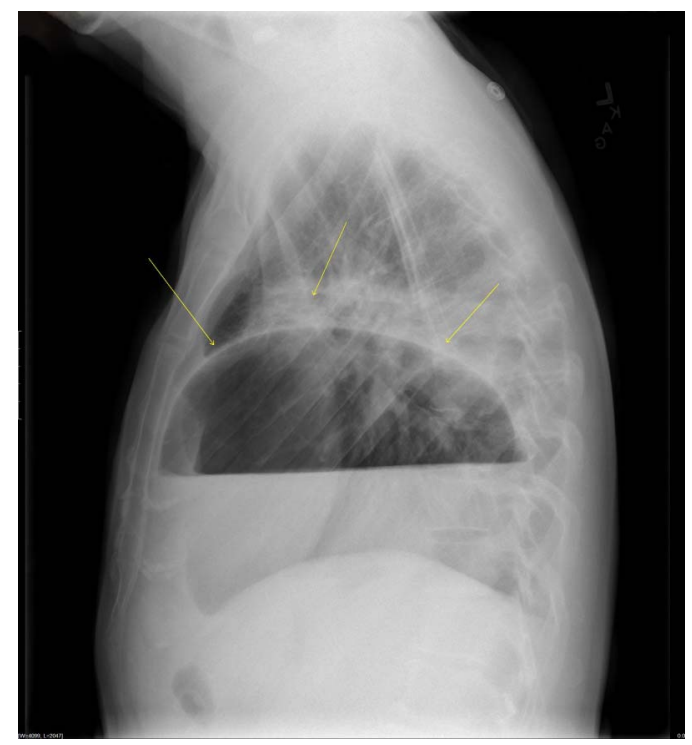

Figure 2 Lateral view of the chest and abdominal X-ray showing a single large hemi-spherical gas bubble in the chest and upper abdomen, characteristic of gastric herniation. 


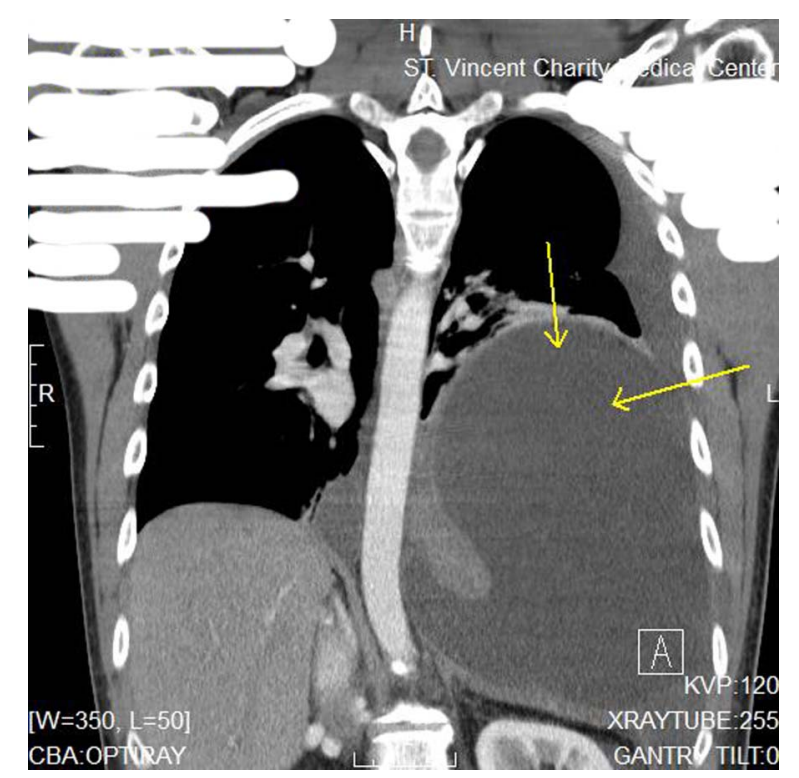

Figure 3 CT of the thorax showing herniation of nearly the entire stomach into the left thoracic space and associated severe gastric distension with air and fluid.

abdomen. On reduction, $60 \%$ of the stomach was found to be necrotic, and it was decided to convert to exploratory laparotomy. The patient underwent a total gastrectomy. The defect in the diaphragm was closed with interrupted suture. A tissue reinforcement absorbable mesh was applied on the defect to encourage neovascularisation. A biodegradable mesh could be used safely in this contaminated field. The patient was subsequently shifted to intensive care unit, where he had a monthlong stay. He was started on a ventilator, vasopressor support, total parenteral nutrition and intravenous broad-spectrum antibiotics.

Gastric volvulus is classified as primary or secondary, depending on aetiology. Primary gastric volvulus is due to abnormalities of gastric ligaments whereas the secondary is due to paraoesophageal hernia, diaphragmatic hernia, or phrenic nerve paralysis. ${ }^{5}$ Other classifications are based on the type of anatomic rotation, such as organo-axial volvulus, mesenteroaxial and combined. ${ }^{6}$

A careful history of GERD, para-oesophageal hernia and hiatal hernia repair surgery should prompt the diagnosis of acute or chronic gastric volvulus as a differential diagnosis of chest pain. Our patient had a longstanding history of GERD, but he had stopped following up with his physician for the past 1 year. This important history was not duly recognised in prior ER visits. Borchardt's triad, comprising of acute chest pain, severe retching and inability to pass a nasogastric tube, is the classical presentation of acute gastric volvulus. ${ }^{3}$ This is a surgical emergency and, if managed in a timely manner, has a favourable prognosis.

\section{Learning points}

- Gastric volvulus is due to an acute abnormal rotation of the stomach either on the vertical or horizontal axis, causing complete gastric outlet obstruction and, potentially, strangulation.

- Careful history-taking of GERD, para-oesophageal hernia and hiatal hernia repair surgery should prompt the diagnosis of acute or chronic gastric volvulus as a differential diagnosis of chest pain.

- Borchardt's triad, comprising of acute chest pain, severe retching and inability to pass a nasogastric tube, is the classical presentation of acute gastric volvulus.

Competing interests None declared.

Patient consent Obtained.

Provenance and peer review Not commissioned; externally peer reviewed.

\section{REFERENCES}

1 McCaig L, Burt C. National hospital ambulatory medical care survey: 2003 emergency department summary. In: Advance data from vital and health statistics. Atlanta, GA: Centers for Disease Control and Prevention, 2005.

2 Carlson MA, Condon RE, Ludwig KA, et al. Management of intrathoracic stomach with polypropylene mesh prosthesis reinforced transabdominal hiatus hernia repair. J Am Coll Surg 1998;187:227-30.

3 Chau B, Dufel S. Gastric volvulus. Emerg Med J 2007;24:446-7.

4 Godshall D, Mossallam U, Rosenbaum R. Gastric volvulus: case report and review of the literature. J Emerg Med 1999;17:837-40.

5 Wasselle JA, Norman J. Acute gastric volvulus: pathogenesis, diagnosis, and treatment. Am J Gastroenterol 1993;88:1780-4.

6 Rashid F, Thangarajah T, Mulvey D, et al. A review article on gastric volvulus: a challenge to diagnosis and management. Int J Surg 2010;8:18-24.

Copyright 2016 BMJ Publishing Group. All rights reserved. For permission to reuse any of this content visit

http://group.bmj.com/group/rights-licensing/permissions.

BMJ Case Report Fellows may re-use this article for personal use and teaching without any further permission.

Become a Fellow of BMJ Case Reports today and you can:

- Submit as many cases as you like

- Enjoy fast sympathetic peer review and rapid publication of accepted articles

- Access all the published articles

- Re-use any of the published material for personal use and teaching without further permission

For information on Institutional Fellowships contact consortiasales@bmjgroup.com

Visit casereports.bmj.com for more articles like this and to become a Fellow 